\title{
Geomorphological aspects of coast protection in high latitudes
}

\section{V. Afanasiev ${ }^{1}$ \\ E. I. Ignatov ${ }^{2}$}

\author{
${ }^{1}$ Institute of Marine Geology and Geophysics, FEB RAS, \\ Nauka Street, 1B, Yuzhno-Sakhalinsk, Russia \\ ${ }^{2}$ Lomonosov Moscow State University, The Lenin Hills Street, 1, \\ Moscow, Russia
}

\begin{abstract}
The problems related to the protection of settlements located on the coast, mainly on Holocene sand-pebble accumulative formations (barrier islands and spits) of the Okhotsk, Chukchi and Bering seas have been considered. Approaches of solving the problem on the shores of Alaska, Chukotka, Kamchatka, Western Priokhotye and Sakhalin have been compared as well. The evolution of coastal protection solutions on the Arctic and subarctic coasts has been shown. It is concluded that the justification of the design solutions does not always correspond to the level of modern knowledge about the dynamics of the shores. Herewith, the basis for determining long-term trends of erosion of problem areas of the coast is the interpolation of the long-term average data obtained at the analysis of remote sensing materials.

The main trends of erosion of coastal plains and dynamics of Holocene accumulative forms are considered in relevance to the problem of protecting of the coast. Specific features of geomorphological processes on the Arctic and subarctic coasts have been noted. It is concluded that biopositive and safe coastal protection solutions are possible on the basis of a complete set of data about the development and dynamics of the coastal zone of the seas.
\end{abstract}

\section{Keywords}

Coastal erosion, Coastal protection, Freezing beach, Permafrost, Arctic coast, Subarctic sea

\section{References $\mathcal{A}_{\text {PDF }}$}

For citation: Afanasiev V.V., Ignatov E.I. Geomorphological aspects of coast protection in high latitudes. Geosystems of Transition Zones, 2018, vol. 2, N 2, p. 116-124. doi:10.30730/25418912.2018.2.2.116-124 